(2) Open Access Full Text Article

\title{
Improving surveillance system and surgical site infection rates through a network: A pilot study from Thailand
}

This article was published in the following Dove Press journal:

Clinical Epidemiology

8 May 2009

Number of times this article has been viewed

\author{
Nongyao Kasatpibal' \\ Mette Nørgaard ${ }^{2}$ \\ Silom Jamulitrat ${ }^{3}$ \\ For The Surgical Site \\ Infection Study Group \\ 'Faculty of Nursing, Chiang Mai \\ University, Chiang Mai, Thailand; \\ 2Department of Clinical Epidemiology, \\ Aarhus University Hospital, Aalborg \\ and Aarhus, Denmark; ${ }^{3}$ Department \\ of Community Medicine, Faculty \\ of Medicine, Prince of Songkla \\ University, Songkhla, Thailand
}

Correspondence: Nongyao Kasatpibal Faculty of Nursing, Chiang Mai University, Chiang Mai, Thailand 50200

Tel +66896109890

Fax +6653217145

Email nongyaok2003@yahoo.com
Background: Surveillance of surgical site infections (SSI) provides data upon which interventions to improve patient safety can be based. In Thailand, however, SSI surveillance has not yet been standardized.

Objectives: To develop a standardized SSI surveillance system and to monitor SSI rates after introduction of such a system.

Methods: We conducted a prospective study among 17,752 patients who underwent surgery in ten hospitals in Thailand from April 2004 to May 2005. The SSI rates were computed and benchmarked with the US rates, reported in terms of standardized infection ratio (SIR). We estimated the incidence rate ratio of surgical site infections by comparing the incidence in the last study period with the incidence in the first study period.

Results: The study included 17,869 operations and identified 248 SSIs, yielding an SSI rate of 1.4 infections/100 operations and a corresponding SIR of 0.6 (95\% confidence interval $[\mathrm{CI}]=0.5-0.7)$. During the study period the overall SSI rate decreased from 1.8 infections $/ 100$ operations to 1.2 infections/100 operations, yielding an incidence rate ratio of $0.65(95 \%$ $\mathrm{CI}=0.47-0.89$ ).

Conclusion: Our study highlighted that a standardized SSI surveillance in a developing country can be initiated through a network and may be followed by a decrease in SSI rates.

Keywords: surgical site infection, surveillance, network, Thailand

\section{Introduction}

Surgical site infections (SSIs) are costly and constitute a heavy and potentially preventable burden on both patients and health care providers. ${ }^{1-7}$ In recent years, several countries have established surveillance systems for nosocomial infections on a national basis. ${ }^{8-19}$ Participation in such systems has shown to be associated with a reduction in surgical site infections..$^{20,21}$ In addition, the data can be used for benchmarking, education, policy, and decision making in participating hospitals; ${ }^{9-17,19}$ and for improving the quality of care. ${ }^{9-17,19}$ Therefore, several developed countries ${ }^{9-17,19}$ established a national surveillance network.

In Thailand, a national surveillance network has not yet been established. The SSI surveillance is conducted in different ways in the different hospitals with regards to surveillance method and criteria, data analysis, and feedback. A national database on SSI and interhospital benchmarking of SSI rates in Thailand has thus not been available. We therefore conducted this study to develop a standardized SSI surveillance system, to benchmark and monitor SSI rates, and to improve SSI rates in Thailand. 


\section{Methods}

\section{Setting}

Our study was conducted in 13 hospitals in southern Thailand ( $87 \%$ of all hospitals in southern Thailand) including one university hospital, four tertiary care hospitals affiliated with medical schools, and eight general hospitals. All participating hospitals had a computer in the infection control unit, a hospital computer database, and adequate clinical and laboratory information for diagnosis of SSI. Participation was voluntary and the hospitals were assured of confidentiality of their data. However, two general hospitals dropped out from the study due to insufficient infection control personnel and one general hospital was excluded due to inadequate data quality. Only ten hospitals, approximately $10 \%$ of the hospitals for the whole country and $67 \%$ of the hospitals in southern Thailand, were included in the final analysis.

\section{Network strategies}

We developed a standard form and manual for SSI surveillance and a website. We further developed a software called NISA (Nosocomial Infection Surveillance Application) ${ }^{22}$ which was used for data entry, data analysis, and data interpretation in all participating hospitals. Additionally, we organized four quarterly meetings for the participating hospitals for training and discussion of methodological points, data management, and exchange of participants' experience such as SSI definition, data collection, data analysis, data distribution, and data utilization in infection control practices. The first meeting was conducted before start of data collection. In addition, the researchers visited each study hospital every two to three months in order to facilitate the work, advise, and supervise as they needed, and the participating hospitals could consult the researchers at any time via telephone and email. During the study periods, the participating hospitals could use the NISA software to compute their own SSI rates, standardized infection ratio (SIR), and surgeon-specific rates and SIRs. In addition, the hospitals received pooled data of all participating hospitals stratified by infection and SIR quarterly so they could compare their own data with the network data.

\section{Data collection}

A prospective study was conducted from April 2004 to May 2005. Each participating hospital monitored at least two procedures of interest. The hospital selected procedures to surveillance based on high cost (hospital A, B, and C), high volume (hospital D, E, and F), and both high volume and high incidence (hospital G, H, I, and J). One hospital selected $90 \%$ of the suggested procedures, five hospitals monitored $80 \%$ of the procedures, one hospital monitored $60 \%$ of procedures, and two hospitals monitored $40 \%$ of the procedures. All data were collected by experts in infection control and epidemiology. After one day of training in data collection and diagnosis criteria, infection control nurses (ICNs) in each hospital prospectively collected the pertinent data and recorded the data on the preprinted data collection forms. The collected data included patients' demographic data, diagnosis, operation, antibiotics administered, clinical signs and symptoms of infection, laboratory results including microbiology and serology results, and imaging results.

The patients' medical records, operative notes, anesthetic records, diagnostic imaging reports, microbiology investigation data, and other laboratory results were reviewed. Information on variables related to operative procedure (ie, duration of operation, type of operation, degree of wound contamination, surgeon, and antibiotic prophylaxis) was also reviewed. The American Society of Anesthesiologists (ASA) score on the patients' physical status was identified from anesthetic records. Medical records of the discharged patients in the outpatient department and medical records of the readmitted patients were also reviewed for evidence of infection developing after hospital discharge. In addition, telephoning by health care personnel and mailing to all patients were used as a part of post discharge surveillance in this study. Postoperative follow-up was 30 days after the operative procedure in patients without any implants and one year if an implant was in place. ${ }^{23,24}$

The data from NISA software were checked with the preprinted data collection forms by ICNs in each participating hospitals. Then, both data from NISA software and data collection forms were sent to the research center for rechecking, editing, processing, and analysis. In case of inconsistencies between NISA data and the data collection forms or incomplete information, the data collection forms were sent back to the hospital for rechecking and correction.

\section{Definition}

The US Centers for Disease Control and Prevention (CDC) NNIS System criteria were employed for diagnosing SSI and classifying the cases as superficial incisional, deep incisional, or organ/space SSI. ${ }^{23,24}$ The ASA score was used to measure patient physical status. ${ }^{25}$ The operative procedures were classified according to degree of contamination into one of four classes (clean, clean-contaminated, contaminated, or dirty/infected). The patients' final diagnoses and operations were coded according to the International Classification 
of Disease 10th Revision (ICD-10) and the International Classification of Disease 9th Revision, Clinical Modification (ICD-9 CM), respectively. The operative procedures were also classified and assigned risk index categories according to the NNIS. ${ }^{26}$ In the NNIS risk index the duration of the surgical procedure is defined in terms of the number of minutes that an operation lasts; the 75 th percentile for the duration of a given procedure (as determined on the basis of data from the $\mathrm{CDC}$ ) is rounded up to the nearest hour to produce $\mathrm{T}$, the time point that distinguishes procedures of long and short duration.

\section{Statistical analysis}

Demographic data and antibiotic prophylaxis were expressed as percentages. Thai $\mathrm{T}$-values including percentiles and 95\% confidence interval (CI) were computed. The Thai T-values were stratified by operative procedures, and compared with the NNIS T-values. ${ }^{10}$ Incidence of SSI was calculated, using the NNIS operative procedure categories.

The SIR was computed as the ratio between the observed number of infections and the expected number of events. We computed expected numbers of SIRS as the sum of expected numbers for all risk index categories of specific procedures by applying NNIS rates specific for degree of wound contamination, ASA score, and duration of operation on the study population. ${ }^{27-29}$ We estimated the $95 \%$ CI of SIR assuming a Poisson distribution. ${ }^{27-29}$ The SSI rates were stratified by wound class, ASA score, NNIS risk index, urgency of operation, hospitals, calendar periods (two-month or four-month categories from April 2004 to May, 2005 to increase the statistical precision), and operative procedures.

To compare incidence ratios between the first and the last period of the study we estimated the incidence rate ratio as the ratio of SSI rate in the last period to SSI rate in the first period of the study.

All data analyses were performed using the statistical software STATA version 9 (Stata Corp, College Station, TX).

\section{Results}

\section{Patient characteristics}

The study included ten hospitals with 17,752 patients who underwent 17,869 operations. Women accounted for $77.1 \%$ of the studied patients. The median patient age (interquartile range) was 30 (23 to 38 ) years and the overall mortality rate was $0.5 \%$. The median lengths (interquartile range) of preoperative, postoperative, and total hospital stay were 0 ( 0 to 1 ), 4 (3 to 5), and 4 (3 to 6) days, respectively.

\section{The use of antibiotic prophylaxis}

Eighty-eight percent of the patients received antibiotic prophylaxis. The three most common antibiotics used for prophylaxis were ampicillin (35.6\%), cefazolin (12.4\%), and amoxicillin (12.1\%). Antibiotic prophylaxis was administered for more than 24 hours after the operation in $62 \%$ of the cases.

\section{Operation characteristics}

Among 17,869 operations, 46.2\% were classified as emergency. The median duration of operation (interquartile range) was 45 (30 to 65) minutes. The proportion of operations in which the Thai T-values exceeded the 75th percentile NNIS T-values varied among the different operative procedures, ranging from $0 \%$ in laparotomy to $70.2 \%$ in knee prosthesis operations. Colon surgery, hip prosthesis, knee prosthesis, and laminectomy had substantially longer duration of operation than the NNIS, but the durations of mastectomy, cholecystectomy, and hysterectomy were similar to the NNIS. Thus overall, only $16.7 \%$ of procedures in Thailand exceeded the 75 th percentile NNIS T-values (Table 1).

\section{Incidence of SSI and SIR}

In total, 248 SSIs were identified in 17,869 operations, accounting for an overall crude SSI rate of 1.4 infections $/ 100$ operations and a corresponding SIR of $0.6(95 \% \mathrm{CI}=0.5-0.7)$. Most SSIs were classified as superficial SSI (69.8\%), followed by deep incisional SSI (19.7\%) and organ/space SSI (10.5\%). Thirty-one percent of the deep incisional SSIs occurred after cesarean section, followed by $27 \%$ after appendectomy and open reduction fracture procedures, respectively. Organ/space SSIs occurred mostly after craniotomy (31\%), followed by hysterectomy (19\%), and open reduction fracture procedures $(15 \%)$, respectively.

Of the 248 SSIs, 107 SSIs (43.1\%) were detected after hospital discharge. The majority of the post discharge SSIs occurred in cesarean section, appendectomy, and open reduction fracture procedures. Among the SSIs detected after discharge, $45 \%$ were identified through follow-up in the out patient clinic, $31 \%$ from telephoning by health care personnel, and $24 \%$ from mailing. The incidences of SSIs and the SIR (95\% CI) stratified by characteristics are shown in Table 2. All ten participating hospitals seemed to reduce their SSI rates during the study period (Table 3-4), although the statistical precision was low. Overall, however, the SSI rate decreased from 1.8 infections/100 operations to 1.2 infections/100 operations, yielding an incidence rate ratio of $0.65(95 \% \mathrm{CI}=0.47-0.89)$ within 14 months. 
Table I 75th percentile of duration of operation ( $T$ value) stratified by operative procedures

\begin{tabular}{|c|c|c|c|c|c|c|c|}
\hline \multirow[t]{2}{*}{ Operative procedures } & \multirow{2}{*}{$\begin{array}{l}\text { Hospitals } \\
\text { No. }\end{array}$} & \multirow{2}{*}{$\begin{array}{l}\text { Operations } \\
\text { No. }\end{array}$} & \multirow{2}{*}{$\begin{array}{l}\text { 75th percentile } \\
\text { NNIS T value } \\
\text { Hours }\end{array}$} & \multicolumn{3}{|c|}{ 75th percentile Thai T value } & \multirow{2}{*}{$\begin{array}{l}\text { Exceeded 75th } \\
\text { percentile NNIS } \\
\text { T value (\%) }\end{array}$} \\
\hline & & & & Hours & Minutes & $95 \% \mathrm{Cl}$ & \\
\hline Appendectomy & 9 & 3,358 & I & 0.75 & 45 & $45-45$ & 11.52 \\
\hline Cholecystectomy & 4 & 295 & 2 & 1.92 & 115 & $100-120$ & 21.36 \\
\hline Colon surgery & 2 & 176 & 3 & 3.75 & 225 & $210-245$ & 48.30 \\
\hline Craniotomy & 4 & 651 & 4 & 4.33 & 260 & $245-280$ & 36.25 \\
\hline Herniorrhaphy & 7 & 951 & 2 & 1.08 & 65 & $60-70$ & 8.10 \\
\hline Mastectomy & 2 & 145 & 3 & 2.75 & 165 & $154-185$ & 23.45 \\
\hline Small bowel & I & 18 & 3 & 1.94 & 116 & $85-229$ & 11.11 \\
\hline Laparotomy & 1 & 10 & 2 & 0.92 & 55 & $36-65$ & 0.00 \\
\hline Open reduction of fracture & 7 & $|| 7 \mid$, & 2 & 1.42 & 85 & $80-90$ & 8.63 \\
\hline Knee prosthesis & 2 & 84 & 2 & 2.50 & 150 & $142-155$ & 70.24 \\
\hline Hip prosthesis & 2 & 35 & 2 & 2.75 & 165 & $150-183$ & 51.43 \\
\hline Laminectomy & 3 & 87 & 2 & 3.42 & 205 & $180-225$ & 66.67 \\
\hline Spinal fusion & I & 16 & 4 & 3.98 & 239 & $|54-33|$ & 12.50 \\
\hline Other musculoskeletal & I & 19 & 3 & 1.17 & 70 & $59-117$ & 5.26 \\
\hline Cesarean section & 9 & 9,851 & I & 0.92 & 55 & $55-55$ & 16.78 \\
\hline Hysterectomy & 7 & 972 & 2 & 1.92 & 115 & $110-120$ & 20.99 \\
\hline Other genitourinary & I & 30 & 2 & 1.00 & 60 & $50-85$ & 3.33 \\
\hline Total & & & - & - & - & - & 16.68 \\
\hline
\end{tabular}

Abbreviation: NNIS, National Nosocomial Infection Surveillance system.

Table 2 Surgical site infection rates (infections/I00 operations) and standardized infection ratios (SIR) stratified by characteristics

\begin{tabular}{|c|c|c|c|c|c|}
\hline Characteristics & Operations No. & Infections No. & $\begin{array}{l}\text { Rate of infections/ } 100 \\
\text { operations }\end{array}$ & SIR & $95 \% \mathrm{Cl}$ \\
\hline \multicolumn{6}{|l|}{ Wound class } \\
\hline Clean & 2,894 & 36 & 1.2 & 1.0 & $0.7-1.4$ \\
\hline Clean-contaminated & $|4,03|$ & 158 & I.I & 0.5 & $0.4-0.5$ \\
\hline Contaminated & 675 & 29 & 4.3 & 1.2 & $0.8-1.8$ \\
\hline Dirty/infected & 269 & 25 & 9.3 & 3.2 & $1.3-6.3$ \\
\hline \multicolumn{6}{|l|}{ ASA classification } \\
\hline I & 12,552 & 140 & I.I & 0.5 & $0.4-0.5$ \\
\hline II & 4,704 & 94 & 2.0 & 0.9 & $0.8-1.1$ \\
\hline III & 539 & 11 & 2.0 & 0.7 & $0.4-1.1$ \\
\hline IV & 67 & 3 & 4.5 & 2.0 & $0.1-9.1$ \\
\hline v & 7 & 0 & 0.0 & 0.0 & - \\
\hline \multicolumn{6}{|c|}{ NNIS risk index category } \\
\hline 0 & 13,689 & 132 & 1.0 & 0.5 & $0.4-0.5$ \\
\hline 1 & 3,844 & 98 & 2.5 & 0.8 & $0.7-0.9$ \\
\hline 2 & 314 & 18 & 5.7 & 1.2 & $0.7-1.9$ \\
\hline 3 & 22 & 0 & 0.0 & 0.0 & - \\
\hline \multicolumn{6}{|l|}{ Type of operation } \\
\hline Elective & 9,610 & 142 & 1.5 & 0.7 & $0.6-0.8$ \\
\hline Emergency & 8,259 & 106 & 1.3 & 0.5 & $0.5-0.6$ \\
\hline Total & 17,869 & 248 & 1.4 & 0.6 & $0.5-0.7$ \\
\hline
\end{tabular}

Abbreviations: ASA, American Society of Anesthesiologists; NNIS, National Nosocomial Infection Surveillance system; NNIS risk index, the National Nosocomial Infection Surveillance system risk index consists of duration of operation, wound class, and ASA score. 
Table 3 Surgical site infection rates (infections/I00 operations) and standardized infection ratios (SIR) stratified by study periods

\begin{tabular}{|c|c|c|c|c|c|}
\hline Period & Operations No. & Infections No. & $\begin{array}{l}\text { Rate of infections/ } 100 \\
\text { operations }\end{array}$ & SIR & $95 \% \mathrm{Cl}$ \\
\hline April 2004-May 2004 & 1,749 & 31 & 1.8 & 0.8 & $0.6-1.1$ \\
\hline June 2004-July 2004 & 2,910 & 53 & 1.8 & 0.8 & $0.6-1.0$ \\
\hline August 2004-September 2004 & 2,624 & 35 & 1.3 & 0.6 & $0.4-0.7$ \\
\hline October 2004-November 2004 & 2,648 & 38 & $\mathrm{I} .4$ & 0.6 & $0.5-0.8$ \\
\hline December 2004-January 2005 & 2,608 & 29 & I.I & 0.5 & $0.4-0.6$ \\
\hline February 2005-March 2005 & 2,700 & 30 & 1.1 & 0.5 & $0.4-0.6$ \\
\hline April 2005-May 2005 & 2,630 & 32 & 1.2 & 0.5 & $0.4-0.6$ \\
\hline Total & 17,869 & 248 & 1.4 & 0.6 & $0.5-0.7$ \\
\hline
\end{tabular}

For the procedures with at least 50 operations, the SSI rates were stratified by procedure and NNIS risk index. No infections occurred in the NNIS risk index categories 2 and 3 , (data not shown) (Table 5).

\section{Discussion}

Our study showed that we were able to develop a SSI surveillance network in Thailand which seemed to fulfill the requirements for an effective surveillance system. Implementation of the system may be followed by a reduction in SSI rates in all participating hospitals.

The possibility of developing a network in a limited resource country such as Thailand is consistent with previous reports from developed countries. ${ }^{9-17,19}$ The NISA software allowed adequate and timely feedback of SSI rates in Thailand ${ }^{30}$ because of easy access for the participating hospitals to compute their own infection rates and to create a timely report. In developing countries where the internet may not be easy to access in all parts of the country, the stand alone software could be more appropriate than web-based software used in the developed countries. ${ }^{9-17,19}$

In our study, the participating hospitals could benchmark their rates with pooled data provided by the research center, and had the opportunity to share their experience with other network members and experts every three months. This may explain the overall decrease we found in infection rates due to improved quality of surgical care. ${ }^{31,32}$ The findings were similarly to reports from the developed countries. ${ }^{9-17,19}$ These strategies may thus apply to other developing countries. We found a decrease of SSI rates over the study period in all 10 hospitals. Our statistical precision is, however, low and this may be a chance finding. Prolonged surveillance would increase the sample size and thereby improve the precision ${ }^{33}$ of the reduction in SSI rate in each participating hospital.

Table 4 Comparing surgical site infection (SSI) rates (infections/I00 operations) and rate ratios between the first period and the last period stratified by hospitals

\begin{tabular}{|c|c|c|c|c|c|c|c|c|}
\hline \multirow[t]{2}{*}{ Hospital } & \multicolumn{3}{|c|}{ First period (April-July 2004) } & \multicolumn{3}{|c|}{ Last period (February-May 2005) } & \multirow[t]{2}{*}{ Rate ratio $^{a}$} & \multirow[t]{2}{*}{$95 \% \mathrm{Cl}$} \\
\hline & $\begin{array}{l}\text { Operations } \\
\text { No. }\end{array}$ & $\begin{array}{l}\text { Infections } \\
\text { No. }\end{array}$ & $\begin{array}{l}\text { Rate of infections/ } 100 \\
\text { operations }\end{array}$ & $\begin{array}{l}\text { Operations } \\
\text { No. }\end{array}$ & $\begin{array}{l}\text { Infections } \\
\text { No. }\end{array}$ & $\begin{array}{l}\text { Rate of infections/ I } 00 \\
\text { operations }\end{array}$ & & \\
\hline A & 579 & 8 & 1.38 & 534 & 6 & 1.12 & 0.81 & $0.28-2.33$ \\
\hline B & 843 & 12 & 1.42 & 1063 & 6 & 0.56 & 0.40 & $0.15-1.05$ \\
\hline C & 396 & 6 & 1.52 & 472 & 4 & 0.85 & 0.56 & $0.16-1.96$ \\
\hline $\mathrm{D}$ & 434 & 8 & 1.84 & 624 & 6 & 0.96 & 0.52 & $0.18-1.49$ \\
\hline $\mathrm{E}$ & 594 & 11 & 1.85 & 556 & 8 & 1.44 & 0.78 & $0.31-1.92$ \\
\hline $\mathrm{F}$ & 376 & 7 & 1.86 & 498 & 4 & 0.80 & 0.43 & $0.13-1.46$ \\
\hline G & 623 & 12 & 1.93 & 681 & 11 & 1.62 & 0.84 & $0.37-1.89$ \\
\hline $\mathrm{H}$ & 328 & 7 & 2.13 & 340 & 6 & 1.76 & 0.83 & $0.28-2.43$ \\
\hline I & 132 & 3 & 2.27 & 126 & 2 & 1.59 & 0.70 & $0.12-4.11$ \\
\hline J & 354 & 10 & 2.82 & 436 & 9 & 2.06 & 0.73 & $0.30-1.78$ \\
\hline Total & 4,659 & 84 & 1.80 & 5,330 & 62 & 1.16 & 0.65 & $0.47-0.89$ \\
\hline
\end{tabular}

Note: aRate ratio, ratio of SSI rate in the last period to SSI rate in the first period; $95 \% \mathrm{Cl}, 95 \%$ confidence intervals of rate ratio. 
Table 5 Surgical site infection rates (infections/I00 operations) stratified by operative procedures and NNIS risk index

\begin{tabular}{|c|c|c|c|c|}
\hline Operative procedures & NNIS risk index ${ }^{a}$ & No. of operations & No. of infections & Rate of infections/ 100 operations \\
\hline \multirow[t]{3}{*}{ Appendectomy } & 0 & 2,673 & 32 & 1.20 \\
\hline & I & 599 & 25 & 4.17 \\
\hline & 2 & 84 & 8 & 9.52 \\
\hline \multirow[t]{2}{*}{ Cholecystectomy } & 0 & 193 & 7 & 3.63 \\
\hline & 1 & 89 & 4 & 4.49 \\
\hline \multirow[t]{3}{*}{ Colon surgery } & 0 & 37 & 2 & 5.41 \\
\hline & I & 80 & 9 & 11.25 \\
\hline & 2 & 51 & 2 & 3.92 \\
\hline \multirow[t]{3}{*}{ Craniotomy } & 0 & 167 & I & 0.60 \\
\hline & I & 397 & 7 & 1.76 \\
\hline & 2 & 81 & 3 & 3.70 \\
\hline \multirow[t]{2}{*}{ Herniorrhaphy } & 0 & 825 & 7 & 0.85 \\
\hline & 1 & 121 & 2 & 1.65 \\
\hline \multirow[t]{2}{*}{ Mastectomy } & 0 & 107 & 0 & 0.00 \\
\hline & I & 38 & 59 & 2.63 \\
\hline \multirow{3}{*}{$\begin{array}{l}\text { Open reduction } \\
\text { of fracture }\end{array}$} & 0 & 828 & 9 & 1.09 \\
\hline & I & 316 & 12 & 3.80 \\
\hline & 2 & 26 & 4 & 15.38 \\
\hline \multirow[t]{2}{*}{ Knee prosthesis } & 0 & 23 & 0 & 0.00 \\
\hline & 1 & 58 & I & 1.72 \\
\hline \multirow[t]{2}{*}{ Cesarean section } & 0 & 7,981 & 59 & 0.74 \\
\hline & 1 & 1,835 & 34 & 1.85 \\
\hline \multirow[t]{2}{*}{ Hysterectomy } & 0 & 745 & 14 & 1.88 \\
\hline & 1 & 214 & 3 & 1.40 \\
\hline
\end{tabular}

Note: aNNIS risk index, The National Nosocomial Infection Surveillance system risk index consists of duration of operation, wound class, and ASA score. Abbreviations: ASA, American Society of Anesthesiologists; NNIS, National Nosocomial Infection Surveillance system.

The overall SSI rate in our study was lower than the rate reported recently from the CDC. ${ }^{10}$ This may be because of incomplete post discharge surveillance, ${ }^{28,30}$ prolonged used of antibiotic prophylaxis beyond the current guideline, ${ }^{34,35}$ or because of less severity ill among surgical patients in Thailand than those in the US. After we stratified the SSI rates by procedures and the NNIS risk index, most SSI rates were comparable to the current studies from the EU., ${ }^{9}$

After two years of follow-up, all ten study hospitals were able to maintain the developed SSI surveillance system and to continue their participation in the network. Hopefully, the positive outcomes from this study may inspire the other Thai hospitals to enter the network because they would gain some benefit free of charge.

The study has also shown that applying previous knowledge $^{28,30}$ and continuing seeking for appropriate strategy to fulfill the gap may lead to achieve the setting goal to reduce the SSI rates such as in Thailand.
The strengths of this study were that we could use standard definitions and methods, ${ }^{23,24}$ and benchmarking data with the NNIS system. ${ }^{10}$ In addition, the data were collected and analyzed by trained personnel and rechecked by the researchers, and all SSIs were confirmed by the experts in infection control for ensuring valid data. Each participating hospital selected its own procedures of interest to surveillance. Although this was a strength for the individual hospital since the system this way could help problem solving in each hospital, it may have introduced a selection bias if procedures left out of the study had a higher or lower SSI rate than expected. Other countries have chosen to monitor the surgical procedures which are commonly performed in all hospitals..$^{9,11-17,19}$ Following that strategy Thai national surveillance on SSI could initially concentrate on colon surgery, appendectomy, open reduction fracture, craniotomy, and cholecystectomy which are commonly performed in most general hospitals, tertiary care hospitals, and 
university hospitals in Thailand. In addition, the incidence of SSI in these procedures is quite high. ${ }^{28}$

Our study has other limitations. For several procedures we had small sample sizes which lowered our statistical precision. This limitation is also seen in previous studies. ${ }^{27,28,30}$ However, selecting common procedures for surveillance and increasing the number of participating hospitals should increase the precision. This inadequacy impelled us to use the 75th percentile NNIS T-values as a cut-point of time for applying to calculate the SIRs in this study which may be inappropriate because only $16.7 \%$ of procedures exceeded the 75th percentile NNIS T-values for the overall procedures. This may affect to the accuracy of the SIRs in our study. The difference in T-values between the NNIS and Thai may be due to differences in surgeon expertise.

The SSI risk differ by surgical procedure..$^{7,36,37}$ To take into account, we consider it a strength that we were able to standardized the SSI rate using the NNIS risk index which has been shown to correlate linearly with adjusted SSI rates and it has been widely used as a national and international benchmarking tool. ${ }^{34}$

We included all operations that met the NNIS operative criteria and were selected by a hospital to be monitored. However, selection bias may have occurred if the hospitals selected the procedures in which they had a lower than average incidence of SSI. This will make us underestimate the SSI rates. Conversely, if the hospitals selected the procedures with a higher than average incidence of SSI, it would result in overestimation of the SSI rates. We find the latter scenario most likely because the hospitals aimed to improve their SSI rates. Three hospitals had dropped out from the study after they were included in the study. This may lead to selection bias due to loss to follow up.

Lastly, incomplete post-discharge surveillance in Thailand may have led us to underestimated SSI rates. Although all participating hospitals intended to follow all patients included in the study after hospital discharge, only $72 \%-85 \%$ of these could be pursued. We do not, however, expect the post-discharge surveillance to be less complete in the last part of our study period and incomplete post-discharge surveillance therefore cannot explain the decreasing SSI rates we found after implementation of the surveillance system. If a hospital had a smaller or a higher inclusion of post-discharge surveillance than the average, the hospital should, however, interpret their benchmarked data with caution. Improving post-discharge surveillance in Thailand would lead to more accurate SSI rates.

In conclusion, a standardized SSI surveillance, relevant preliminary benchmarked data, and a reduction in the overall
SSI rate in a developing country could be achieved through a SSI network.

\section{Acknowledgments}

We thank the directors of participating hospitals, infection control nurses, hospital wards, other clerical staff, and others who assisted with the data collection. This work was funded by the Health Systems Research Institute, Thailand. The Surgical Site Infection Study Group: Songklanagarind Hospital: Somchit Thongpiyapoom, RN; Hat Yai Hospital: Dararat Dumrongkullachart, RN, MNS; Vachira Phuket Hospital: Wilailuk Wongchunlachat, RN, MNS; Naradhiwas Rajanagarindra Hospital: Doungporn Nukoonruk, RN, MNS; Satun Hospital: Prakob Thongjib, RN, MNS; Trang Hospital: Saranya Jarupanich, RN, MNS; Nattaree Jirayuwattanakul, RN; Phatthalung Hospital: Chudee Rittichu, RN, MSc; Suratthani Hospital: Chonlada Tiwpong, RN, MNS; Yala Hospital: Chumpunuch Chaimanee, RN, MA; Pattani Hospital: Penkhae Pimolsettapun, RN; Songkhla Hospital: Supornsri Sepmongkollert, RN, MSc.

\section{Disclosure}

The authors have no conflicts of interest in this work.

\section{References}

1. Olsen MA, Chu-Ongsakul S, Brandt KE, Dietz JR, Mayfield J, Fraser VJ. Hospital-associated costs due to surgical site infection after breast surgery. Arch Surg. 2008;143(1):53-60.

2. Kirkland KB, Briggs JP, Trivette SL, Wilkinson WE, Sexton DJ. The impact of surgical-site infections in the 1990s: attributable mortality, excess length of hospitalization, and extra cost. Infect Control Hosp Epidemiol. 1999;20(11):725-730.

3. Kasatpibal N, Thongpiyapoom S, Narong MN, Suwalak N, Jamulitrat S. Extra charge and extra length of postoperative stay attributable to surgical site infection in six selected operations. J Med Assoc Thai. 2005; 88(8):1083-1091.

4. Hollenbeak CS, Murphy D, Dunagan WC, Fraser VJ. Nonrandom selection and the attributable cost of surgical-site infections. Infect Control Hosp Epidemiol. 2002;23(4):177-182.

5. Graves N, Nicholls TM, Morris AJ. Modeling the costs of hospitalacquired infections in New Zealand. Infect Control Hosp Epidemiol. 2003;24(3):214-223.

6. Graves N, Halton K, Doidge S, Clements A, Lairson D, Whitby M. Who bears the cost of healthcare-acquired surgical site infection? J Hosp Infect. 2008;69(3):274-282.

7. Edwards C, Counsell A, Boulton C, Moran CG. Early infection after hip fracture surgery-risk factors, costs and outcome. J Bone Joint Surg Br. 2008;90(6):770-777.

8. Wilson J, Ramboer I, Suetens C; HELICS-SSI working group. Hospitals in Europe Link for Infection Control through Surveillance (HELICS). Inter-country comparison of rates of surgical site infection-opportunities and limitations. J Hosp Infect. 2007;65 Suppl 2: S165-S170.

9. Szilágyi E, Böröcz K, Gastmeier P, Kurcz A, Horváth-Puhó E. The national nosocomial surveillance network in Hungary: results of two years of surgical site infection surveillance. J Hosp Infect. 2009; 71(1):74-80. 
10. National Nosocomial Infections Surveillance (NNIS) System Report, data summary from January 1992 through June 2004, issued October 2004. Am J Infect Control. 2004;32(8):470-485.

11. Scélo G, Gambotti L, Boulez JC, et al. Missing data and participation or non-participation in a surgical-site infection surveillance network. J Hosp Infect. 2004;56(1):81-82.

12. Rioux C, Grandbastien B, Astagneau P. Impact of a six-year control programme on surgical site infections in France: results of the INCISO surveillance. J Hosp Infect. 2007;66(3):217-223.

13. Muilwijk J, Walenkamp GHIM, Voss A, Wille JC, van den Hof S. Random effect modelling of patient-related risk factors in orthopaedic procedures: results from the Dutch nosocomial infection surveillance network 'PREZIES'. J Hosp Infect. 2006;62(3):319-326.

14. McLaws ML, Taylor PC. The Hospital Infection Standardised Surveillance (HISS) programme: analysis of a two-year pilot. $J$ Hosp Infect. 2003;53(4):259-267.

15. Gikas A, Pediaditis I, Roumbelaki M, et al. Repeated multi-centre prevalence surveys of hospital-acquired infection in Greek hospitals. J Hosp Infect. 1999;41(1):11-18.

16. Geubbels ELPE, Bakker HG, Houtman P, et al. Promoting quality through surveillance of surgical site infections: five prevention success stories. Am J Infect Control. 2004;32(7):424-430.

17. Gastmeier P, Sohr D, Schwab F, et al. Ten years of KISS: the most important requirements for success. J Hosp Infect. 2008;70(Suppl 1):S11-S16.

18. Edwards JR, Peterson KD, Andrus ML, Dudeck MA, Pollock DA, Horan TC. National Healthcare Safety Network (NHSN) report, data summary for 2006 through 2007, issued November 2008. Am J Infect Control. 2008;36(9):609-626.

19. Couris CM, Rabilloud M, Ecochard R, et al. Nine-year downward trends in surgical site infection rate in southeast France (1995-2003). J Hosp Infect. 2007;67(2):127-134.

20. Gastmeier P, Geffers C, Brandt C, et al. Effectiveness of a nationwide nosocomial infection surveillance system for reducing nosocomial infections. J Hosp Infect. 2006;64(1):16-22.

21. Bärwolff S, Sohr D, Geffers C, et al. Reduction of surgical site infections after Caesarean delivery using surveillance. J Hosp Infect. 2006;64(2):156-161.

22. Kasatpibal N, Jamulitrat S. Manual of NISA 1.0 software for nosocomial infection surveillance. Songkhla: Chanmaung; 2004.

23. Horan TC, Gaynes RP, Martone WJ, Jarvis WR, Grace Emori T. CDC definitions of nosocomial surgical site infections. A modification of CDC definitions of surgical wound infections. Am J Infect Control. 1992;20(5):271-274.
24. Horan TC, Andrus M, Dudeck MA. CDC/NHSN surveillance definition of health care-associated infection and criteria for specific types of infections in the acute care setting. Am J Infect Control. 2008;36(5): 309-332.

25. Haberkern CM, Lecky JH. Preoperative assessment and the anesthesia clinic. Anesthesiol Clin North America. 1996;14(4):609-630.

26. Culver DH, Horan TC, Gaynes RP, et al. Surgical wound infection rates by wound class, operative procedure, and patient risk index. Am J Med. 1991;91(3 Suppl 2):S152-S157.

27. Narong MN, Thongpiyapoom S, Thaikul N, Jamulitrat S, Kasatpibal N. Surgical site infections in patients undergoing major operations in a university hospital: using standardized infection ratio as a benchmarking tool. Am J Infect Control. 2003;31(5):274-279.

28. Kasatpibal N, Jamulitrat S, Chongsuvivatwong V. Standardized incidence rates of surgical site infection: A multicenter study in Thailand. Am J Infect Control. 2005;33(10):587-594.

29. Jodra VM, Rodela AR, Martínez EM, Fresneña NL; Quality Control Indicator Working Group. Standardized infection ratios for three general surgery procedures: a comparison between Spanish Hospitals and US Centers participating in the national nosocomial infections surveillance system. Infect Control Hosp Epidemiol. 2003;24(10): 744-748.

30. Kasatpibal N, Jamulitrat S, Chongsuvivatwong V, Nørgaard M, Sørensen HT. Impact of surgeon-specific feedback on surgical site infection rates in Thailand. J Hosp Infect. 2006;63(2):148-155.

31. Khuri SF, Daley J, Henderson WG. The comparative assessment and improvement of quality of surgical care in the department of veterans affairs. Arch Surg. 2002;137(1):20-27.

32. Friedman C, Chenoweth C. Best practice modeling initiative in an infection control program [abstract]. Am J Infect Control. 2005; 33(5):E72.

33. Rothman KJ. Epidemiology: An introduction. Oxford: Oxford University Press; 2002

34. WHO. WHO guidelines for safe surgery. Geneva: WHO Press; 2008.

35. Anderson DJ, Kaye KS, Classen D, Arias KM, Podgorny K, Burstin H, et al. Strategies to prevent surgical site infections in acute care hospitals. Infect Control Hosp Epidemiol. 2008;29(Suppl 1): S51-S61.

36. Haridas M, Malangoni MA. Predictive factors for surgical site infection in general surgery. Surgery. 2008;144(4):496-503.

37. Olsen MA, Lefta M, Dietz JR, Brandt KE, Aft R, Matthews R, et al. Risk factors for surgical site infection after major breast operation. J Am Coll Surg. 2008;207(3):326-335.
Clinical Epidemiology

\section{Publish your work in this journal}

Clinical Epidemiology is an international, peer-reviewed, open access journal focusing on disease and drug epidemiology, identification of risk factors and screening procedures to develop optimal preventative initiatives and programs. Specific topics include: diagnosis, prognosis, treatment, screening, prevention, risk factor modification, systematic

\section{Dovepress}

reviews, risk \& safety of medical interventions, epidemiology \& biostatical methods, evaluation of guidelines, translational medicine, health policies \& economic evaluations. The manuscript management system is completely online and includes a very quick and fair peerreview system, which is all easy to use. 